\title{
Representación y desmitificación del asesino en serie en la trilogía Morirás mañana de Jaime Bayly
}

Recibido: 7/8/2020. Aceptado: 30/12/2020.

\begin{abstract}
Resumen
Este ensayo explora la representación del asesino en serie en la trilogía Morirás mañana de Jaime Bayly. Considerada la expresión más violenta de la masculinidad, el asesino en serie se ha convertido en un ícono cultural debido a la gran atención tanto en los medios como en la literatura. Este trabajo propone que Morirás mañana evita imitar el modelo originario del subgénero de asesino en serie mediante la subversión de las convenciones del modelo, tales como la presencia de representantes de la ley y el restablecimiento del statu quo. La transgresión se manifiesta también en la elección de una estructura narrativa y de un punto de vista diferentes, al igual que en la inserción de este personaje en un contexto de anomia donde la falta de fe en el orden social y en la justicia es la norma. Este trabajo también estudia la singular representación del asesino en serie, Javier Garcés, personaje que dista de la imagen tradicional puesto que su violencia no va dirigida exclusivamente a las mujeres ni es de naturaleza sexual. Este trabajo concluye que, debido a la transgresión del subgénero y a la representación no genérica del homicida, la obra de Bayly desmitifica la figura del asesino serial.
\end{abstract}

Palabras clave: subgénero del asesino en serie; asesino en serie; masculinidad; anomia; crimen.

\section{Serial Killer representation and demythification in Jaime Bayly's trilogy Morirás mañana}

\begin{abstract}
This essay studies the representation of the serial killer in Jaime Bayly's Morirás mañana. Serial killing is considered by experts as the most violent expression of masculinity. Some serial killers have become cultural icons in America. This paper proposes that Morirás mañana eludes imitating the serial killer subgenre by subverting the original serial killer subgenre model's conventions, such as the presence of representatives of the law and the reestablishment of the status quo. This transgression
\end{abstract}


also happens because of the selection of a different narrative structure and point of view, as well as the serial killer's insertion in an anomie context characterized by the lack of faith in social order and justice. This work analyzes the unique representation of the trilogy's serial killer, Javier Garcés, who distances himself from the traditional serial killer image since his violence is not exclusively directed to women, nor is it of a sexual nature. This essay concludes that by avoiding the serial killer subgenre's convention and by its non-generic representation of the murderer, Morirás mañana demythifies the serial killer.

Keywords: serial killer subgenre; serial killer; masculinity; anomie; crime.

\section{Introducción}

Gracias a la publicación de su primera novela, No se lo digas a nadie, en 1994, el escritor peruano Jaime Bayly ingresa en el mundo de las letras causando un verdadero furor al "descubrirle" a la sociedad peruana el "oscuro" mundo de la homosexualidad que existía en el país, especialmente en la ciudad de Lima. La indignación y el interés que provoca esta y sus siguientes novelas se deben, en parte, a los elementos biográficos presentes en ellas que propician leerlas como un roman à clef. A pesar de su carácter escandaloso, estas novelas le permiten al autor explorar el tema de la marginalidad a través de sus personajes socialmente desplazados. En sus últimas obras, exceptuando La lluvia del tiempo (2014), Bayly continúa desarrollando el tema de la marginalización, pero inserta a sus personajes en un contexto de violencia, tal como ocurre en la novela del 2009 El cojo y el loco, cuyos protagonistas son excluidos debido a sus defectos físicos y mentales por fuerzas sociales que atacan, aíslan y, muchas veces, eliminan a aquellos considerados diferentes. Ante esta situación de injusticia, los personajes se rebelan mediante el ejercicio de la violencia y precipitan el caos que se manifiesta en el decurso de la obra a través de delitos menores, secuestros, violaciones sexuales, hasta culminar en un asesinato. Debido a las escenas de violencia y de crimen resultantes de la venganza, no es exagerado señalar que El cojo y el loco se presenta en el universo literario de Bayly como la antesala y preparación de su trilogía de crímenes Morirás mañana, publicada en los años 2010, 2011 y 2012.

Catalogada erróneamente por la editorial Alfaguara como una novela "policiaca o de espionaje" (Orué, 2012), la trilogía Morirás mañana dista diametralmente del género policial en la medida en que la obra carece de la presencia de protectores de la ley, de detectives o de una pesquisa policial que conduzca al esclarecimiento del caso criminal. Bayly desarrolla un texto híbrido cuyo narrador y protagonista, el desahuciado escritor Javier Garcés, revela su identidad de asesino serial en las primeras páginas de la novela al comunicar detalladamente a los lectores sus planes de eliminar a cinco de sus peores enemigos. A diferencia de las novelas detectivescas canónicas, donde el agente policial o detective busca descubrir la identidad del asesino y una causalidad psicológica de sus rampantes crímenes, en la primera entrega de la trilogía, Morirás mañana:El escritor sale a matar, Garcés opta por transformarse en un asesino en serie cuando decide tomar la venganza en sus manos: "No puedo evitar mi muerte, pero puedo evitar que ellos asistan a mi muerte; puedo evitar que ellos sonrían, pérfidos, mediocres, canallas, cuando se enteren de que he muerto" (Bayly, 2010: 14). La presencia del suspenso y del restablecimiento del statu quo que se alcanza al descubrir la identidad del asesino, seguido de su aprehensión y castigo al final de la obra, comunes en el thriller o novela negra, son reemplazados por la indiferencia de una sociedad ante los múltiples crímenes que comete el protagonista en Morirás mañana y por la parálisis de un Estado que no se preocupa (y mucho menos se ocupa) por indagar las causas de la muerte de sus propios ciudadanos. Paralelamente, el entorno de impunidad en el que ocurren los asesinatos como resultado de la anomia omnipresente 
se configura como un mal que no solo acontece en suelo peruano, sino que también afecta al resto del territorio latinoamericano. Garcés expande sus actividades homicidas hacia Chile y Argentina, crímenes que se desarrollan en el segundo y tercer libro de la trilogía respectivamente.

Teniendo como marco referencial el estudio de Philip L. Simpson, Psycho Paths: Tracking the Serial Killer Through Contemporary American Film and Fiction, en el cual se articulan las convenciones del subgénero que el autor denomina Serial Killer Fiction, este ensayo tiene como primer objetivo establecer que la trilogía de Jaime Bayly Morirás mañana transgrede el modelo original de las novelas de asesinos en serie. Esta transgresión se produce no solo a partir de la elección de una estructura narrativa y de un punto de vista diferentes que comparten los tres libros, sino también por el contraste que existe entre la sociedad estadounidense y la latinoamericana: la situación de anomia, la falta de fe en el orden social y en la justicia que aquejan a esta última. Por otro lado, este trabajo estudia la singular representación del asesino Javier Garcés, personaje que dista de la imagen tradicional del asesino serial puesto que su violencia no se dirige exclusivamente a las mujeres ni es de naturaleza sexual. En su lugar, este trabajo enfatiza que la conducta criminal de Garcés es ambigua si se toma en cuenta el perfil psicológico del FBI. La conclusión es que gracias a la subversión de las convenciones del subgénero y la representación de la figura de Garcés, la trilogía de Jaime Bayly desmitifica la figura del homicida serial, que tanto en la realidad como en la ficción canónica se ha glorificado al punto de convertirse en un ícono cultural (Oates, 1999: 233).

\section{El subgénero de la ficción de asesinos en serie}

Entre los estudios analíticos sobre la producción literaria y fílmica que cuenta con la participación antagónica de un asesino en serie, el trabajo de Phillips L. Simpson, Psycho Paths: Tracking the Serial Killer Through Contemporary American Film and Fiction, es uno de los primeros en clasificar estos textos dentro del subgénero de novelas de asesinos en serie. Simpson no solamente acuña este término, sino que explora los orígenes de este tipo de narrativa, establece sus convenciones literarias más destacadas y analiza su evolución a partir de obras tanto fílmicas como literarias, realizadas durante las dos últimas décadas del siglo pasado. Según Simpson, la popularidad de este subgénero se debe a que el asesino en serie se ha configurado como el monstruo de nuestros días, ya que ha logrado alcanzar "a legendary status, largely through clever textual strategies that relocate the monstrous face behind the human one" (Simpson, 2000: 3). El autor también puntualiza que los orígenes de la ficción de este tipo de homicida siguen una rica tradición literaria, que se refleja en la caracterización del homicida en serie en la medida en que este se configura como "a dark patchwork of earlier genre depictions of multiple murderers and folkloric threatening figures" (2000: 14). Entre ellos, el asesino serial se destaca por ser:

a fantastic confabulation of Gothic/romantic villain, literary vampire and werewolf, detective and "pulp" fiction conceits, film noir outsider, frontier outlaw, folkloric threatening figure and nineteenth-century pseudo-sociological conceptions of criminal types given contemporary plausibility. (Simpson, 2000: 15)

No solamente la caracterización del asesino en serie sigue la tradición gótica literaria hasta el punto en que Simpson lo singulariza como "a neo-Gothic villain" (2000: 15), sino que la estructura narrativa del subgénero sigue las convenciones de la literatura gótica: "Such a story typically reduces complex issues of modern communal existence into individual Gothic melodrama relayed in a reassuringly traditional, linear narrative form" (2000: 19). Sin embargo, a pesar de que el subgénero gira en torno al 
pesimismo sobre la incontrolable naturaleza humana que encarna el asesino en serie, en las novelas más convencionales, este personaje no goza de un papel protagónico, sino que se le desplaza a un rol secundario, el de antagonista. Esto se debe, en parte, a que el subgénero de asesino en serie típicamente sigue la estructura de la novela detectivesca, donde el detective o el perfilador criminal tiene el rol protagónico. Su participación tiene como objetivo desenredar el laberinto creado por el homicida con sus múltiples asesinatos con la finalidad de restablecer el statu quo. En este tipo de ficción, la presencia del antagonista aparece casi siempre oculta, por no decir invisible, a los lectores; mientras que sus crímenes, aparentemente fortuitos y muchas veces no descritos en el devenir de la novela, se convierten en las pistas que facilitan el descubrimiento de su identidad gracias a la inteligencia del detective.

Simpson sostiene que las novelas de asesinos en serie revelan casos extremos que evidencian la tendencia del ser humano hacia la maldad (2000: 14). En las obras de ficción del subgénero, el detective no sólo se encarga de hallar al culpable, sino también de especular acerca de por qué ciertos individuos son capaces de cometer tan terribles crímenes. Consecuentemente, este tipo de ficción se configura como un estudio psicoanalítico que trata de explicar la patología del victimario a partir de las pistas que deja en el lugar del crimen para establecer un patrón de conducta que sirva para predecir la identidad de la futura víctima o para acorralar finalmente al homicida. Sobre las causas que motivan los crímenes, Simpson señala que "fictional serial killers' motives are usually more metaphysically, psychologically, and culturally grandiose [...] than those of their real-life counterparts" (2000: 21). Pero es necesario observar que, en las más recientes variantes del género, muchos novelistas han optado por evitar establecer las causas que llevan a los criminales a cometer dichos asesinatos, lo cual impide la construcción de un cuadro psicológico. En estos textos, no existe conexión alguna entre el pasado del criminal y sus horrendos crímenes. En su lugar, estas nuevas representaciones del asesino en serie tratan de enfatizar que este es la representación de las fuerzas del mal que acecha a la sociedad y que, sin razón alguna, mata por el único y malévolo placer que conlleva dominar, torturar y eliminar a sus víctimas.

Debido a su origen gótico, las novelas pertenecientes a la narrativa de asesinos en serie se caracterizan por su naturaleza maniquea; estas obras tienden a reducir la realidad a una perspectiva binaria del bien versus el mal. Siguiendo esta formulación maniquea, el asesino en serie se configura como la expresión pluscuamperfecta de la maldad, mientras que el detective se coloca en la trama en la posición de héroe; no obstante, estos guardianes de la ley emplean frecuentemente las mismas tácticas criminales del victimario para atraparlo. Sobre el maniqueísmo en la literatura de los homicidas en serie, Phillip Jenkins señala que este subgénero "reduces a quite complex and behavioral problem to a personalized, almost gladiatorial conflict between individual heroes and villains, and both sides are presented in accordance with traditional images and stereotypes" (1994: 111). Asimismo, la captura del homicida en serie se presenta como la reafirmación de las leyes del patriarcado y el restablecimiento de un sentido de orden que había sido perturbado por los crímenes múltiples:

Profiling is ultimately enthroned as an effective tool to stop the crimes committed by serial killers, and law-enforcement agents -armed with science, technology and/ or the security of being morally right- single out and capture the subversive agent and re-establish a sense of order. (Santaulària, 2007: 57)

Las convenciones del subgénero de la ficción de los asesinos en serie planteadas por Simpson, en resumen, toman en cuenta tanto su tradición literaria, especialmente la gótica, como el entorno social en el que se desarrolla la trama de estas novelas, un contexto basado en el respeto a las leyes y al derecho a la justicia. Considerando el contexto latinoamericano, es necesario preguntarse si este tipo de narrativa o el 
tema de los asesinos en serie se ha (re)producido en la región y quiénes han sido los escritores que han incursionado en este subgénero. Asimismo, es importante explorar si las obras que existen bajo este subgénero son simplemente una imitación que sigue fielmente el esquema tradicional que viene desde el extranjero, o si sus autores han considerado las diferencias estructurales, tanto culturales como sociales, que distinguen a la sociedad hispana.

\section{Panorama del subgénero de asesinos en serie en Latinoamérica}

Si se realiza un recorrido del panorama de este subgénero dentro de la literatura latinoamericana, se observa que existen pocos ejemplos de la ficción de homicidas en serie. Esto se debe, en primer lugar, a que este fenómeno editorial y cultural se ha originado y desarrollado en los Estados Unidos, donde la cifra de los casos reales de este tipo de crímenes es bastante elevada. De hecho, se estima que el número de asesinos seriales en el país del norte ha representado el $74 \%$ de todos los casos mundiales (Baelo, 2002: 8). Asimismo, la popularidad de este subgénero narrativo se debe al extremo interés que tiene la sociedad estadounidense por este tema. Mark Seltzer, quien explora el auge de este subgénero en los EE. UU., reconoce que existe una situación a la que denomina "wound culture", a la cual define como una insaciable fascinación por "torn and open bodies and torn and open persons, a collective gathering around shock, trauma, and the wound" (1998: 1). Esta morbosa curiosidad del estadounidense ha sido influenciada por los medios de comunicación, especialmente los informativos. Estos tratan de mantener constantemente informado al público de estos casos homicidas con el fin de atraer a un mayor número de televidentes o de lectores. Este interés morboso por la vida de los asesinos en serie ha permitido que este personaje pase de ser un tema de gran exposición y debate en los noticiosos a formar parte de las artes, entre las que destacan los largometrajes cinematográficos y otras obras de ficción.

Con respecto a la producción literaria realizada por autores hispanoamericanos que tratan este tema, la producción es escasa y sus escritores han recurrido a diversas alternativas literarias. Por ejemplo, Ensayo de un crimen (1944) de Rodolfo Usigli, considerada la primera novela negra mexicana, narra la historia de un aspirante a asesino que intenta cometer el crimen perfecto para volverse famoso. Sin embargo, su fama de asesino no se cristaliza porque sus dos crímenes meticulosamente planeados son cometidos por otros asesinos. Al final de la novela, el protagonista termina convirtiéndose en un homicida común y corriente cuando mata sin premeditación alguna a su esposa, homicidio por el cual lo confinan en un manicomio acusado de un crimen pasional. Por otro lado, La pesquisa (1994), del argentino Juan José Saer, sitúa la historia de los asesinatos múltiples y la investigación detectivesca en París. La monumental novela del chileno Roberto Bolaño, 2666 (2004), con sus múltiples reportes policiales que conforman el capítulo titulado "la parte de los crímenes", le permiten al lector asumir la existencia de uno o más asesinos en serie en vista de "los patrones de violencia que presentan las víctimas" (Cabrera 30).

Otra forma narrativa que representa múltiples homicidios aparece en Colombia en los años 90 del siglo pasado. Estas obras de ficción giran alrededor de un sicario que trabaja para el narcotráfico, y han marcado un hito dentro de la literatura de la región. Sin embargo, el género sicaresco no forma parte de la ficción de asesinos en serie porque el sicario, a diferencia del homicida en serie, no asesina por voluntad propia, sino que es un asesino a sueldo.

Se debe observar, sin embargo, la existencia de dos novelas que giran en torno a asesinos múltiples. En primer lugar, la obra del escritor Horacio Castellanos Mora, 
Baile con serpientes (1996), relata la historia de un sociólogo desempleado, Eduardo Sosa, quien llega no solo a identificarse con un indigente, Jacinto Bustillo, sino que termina asumiendo su identidad después de asesinarlo. En compañía de cuatro serpientes venenosas, Eduardo/Jacinto va en búsqueda de las dos personas que llevaron a Jacinto a su ruina económica y desata con ello una ola de crímenes que trae consigo el caos político y social de una nación. Aunque la novela de Castellanos cuenta con la presencia de un asesino múltiple y desarrolla una pesquisa policial para encontrar al culpable de la masacre, los elementos satíricos (la burla de un gobierno inoperante) y fantásticos (serpientes hablantes y capaces de liquidar fácilmente a todo un pueblo) adquieren en el decurso de la obra mayor importancia y dejan de lado el tema del asesino múltiple, lo cual impide clasificar esta novela como parte del subgénero.

En segundo lugar, No me ignores (2010) del escritor chileno Nicolás Poblete cuenta la historia de un feminicida desde sus primeros crímenes de adolescente hasta su suicidio cuando está a punto de ser capturado por las fuerzas del orden después de haber secuestrado a una joven de dieciséis años. Esta novela, a diferencia de la trilogía de Bayly, sigue muy de cerca las convenciones del subgénero de asesinos seriales: los crímenes son de naturaleza sexual, las víctimas no tienen identidad propia, sino que son solamente cuerpos con los cuales el homicida sin nombre puede satisfacer sus fantasías sadomasoquistas. Por otro lado, la obra de Poblete se distancia del subgénero en la medida en que el protagonista y único narrador es el mismo asesino; y en que no se advierte la existencia de una investigación policial a lo largo de la trama. El final de la obra es relevante no solo porque el suicidio del feminicida implica el restablecimiento del statu quo, sino principalmente porque su muerte lo glorifica y lo convierte en un mito. La decisión final del asesino "lo equipara con Dios y eleva su superioridad a otro escalón: decidir sobre su muerte" (Vásquez, 2016: 162).

\section{Subversión del subgénero de asesinos en serie en Morirás mañana}

A diferencia de las novelas mencionadas anteriormente, la trilogía de Bayly se destaca porque los numerosos asesinatos que ocurren en el decurso de las tres entregas acontecen exclusivamente en territorio hispanoamericano, no solo peruano, sino también chileno y argentino. A diferencia de la novela 2666 de Bolaño, donde el lector se imagina la presencia de uno o varios asesinos en serie, Bayly no solamente identifica a Javier Garcés como un asesino serial al que le confiere el papel protagónico, sino que el autor permite que el lector ingrese en la mente asesina del personaje gracias a que Garcés cumple el papel de narrador de su propia travesía criminal. Por otro lado, los asesinatos cometidos por el protagonista no tienen como objetivo obtener una ventaja monetaria como ocurre en el género sicaresco; Garcés aniquila a sus enemigos cegado por un sentimiento de venganza tras saber que le quedan pocos meses de vida debido a un tumor cerebral. Después de enterarse de que las noticias de su enfermedad eran falsas, la sed de venganza que propulsa sus asesinatos en la primera entrega se yuxtapone posteriormente al placer de matar por matar en el segundo y tercer libro de la trilogía.

Tras la lectura de la trilogía de Morirás mañana, se puede ver que la obra no sigue fielmente el esquema tradicional del subgénero propuesto por Simpson. En su lugar, Bayly subvierte las convenciones literarias del género de diferentes maneras. En primer lugar, el autor no relega la participación del homicida serial a un rol secundario. Segundo, la novela privilegia la narración en primera persona: permite con ello que el lector ingrese en la psiquis del asesino; así Bayly le entrega al villano la visibilidad textual que se le niega en obras más convencionales. Tercero, la trilogía no da cabida 
a una trama argumental donde participen investigadores o agentes policiales a cargo de las pesquisas. Mediante su ausencia, esta obra hace hincapié en el estado de anomia en que se inserta la sociedad latinoamericana, especialmente cuando Garcés descubre la impunidad de sus crímenes, con lo cual refleja la inoperancia y la indiferencia de las instituciones del Estado. A pesar del estado de anomia omnipresente, Morirás mañana no se perfila como una denuncia social sobre la corrupción y ruptura del Estado, temas propios del género neopolicial. En la trilogía, Garcés se jacta y se aprovecha de esta situación: al darse cuenta de las condiciones de impunidad, el protagonista se siente seguro para seguir asesinando.

En un intento por definir el concepto de la anomia, Jean Ziegler señala que una situación anómica ocurre cuando:

el tejido social está hecho jirones, en la que ninguna norma supraindividual limita la agresividad de los individuos o de los grupos, en la que las pocas instituciones estatales supervivientes ya solo controlan territorios marginales de la vida colectiva [...] La sociedad legal queda minimizada, relegada al margen del acontecer social (citado en Reyes Morris, 2008: 328)

Es decir, un estado anómico se caracteriza por la debilidad que exhiben tanto las instituciones reguladoras del Estado para fiscalizar el cumplimiento de las normas como las instituciones judiciales para sancionar la violación de la ley. Otros críticos como Ernesto Isuani arguyen que el estado de anomia no solamente se puede comprender a partir de la presencia de un estado civil y penal frágil, sino que también depende de "la baja valoración de lo legal y el pesimismo sobre la eficacia de la justicia que están difundidos en la sociedad constituyendo un fenómeno nacional" (1995: 42). Si bien una situación de anomia no conduce necesariamente a la presencia de la violencia y el crimen en la sociedad, históricamente estos llegan a manifestarse en situaciones de anomia. La transgresión de las normas jurídicas se encuentra tan generalizada que el crimen cometido por sus ciudadanos no es considerado, muchas veces, como una transgresión per se, debido a que no existe una línea clara entre lo que se considera justo e injusto. Asimismo, el estado jurídico es tan laxo que el crimen no es universalmente reprobado por los miembros de una sociedad, lo que conduce a que "exista una ausencia de concordancia entre el derecho positivo y la moral individual" (Isuani, 1995: 35). Es por estas razones que el crimen de la llamada "justicia por mano propia" es reflejo del individualismo y del creciente grado de ansiedad e insatisfacción que predomina en un estado anómico. Este tipo de violencia se manifiesta cuando los ciudadanos perciben que las instituciones legales son incompetentes e incapaces de clamar y satisfacer su sed de justicia, lo cual propicia que ellos mismos sean los que busquen alcanzar sus propias aspiraciones de justicia y de venganza mediante el ejercicio de la violencia. Además, la violación de las leyes es permisible al saberse de antemano que los delitos no van a ser sancionados por la ley escrita en papel, mas ignorada en la práctica.

En Morirás mañana, la condición de anomia que sufre la sociedad peruana hace posible que Garcés adopte una conducta homicida en serie. Incluso, es a partir de sus múltiples crímenes que el protagonista se da cuenta de la envergadura del problema anómico en el que vive inmerso el Perú. A comienzos de la primera entrega de la trilogía, Garcés no tiene idea de la magnitud de la situación anómica en el país. Este desconocimiento se refleja en los sentimientos encontrados que experimenta antes de asesinar a su primera víctima, el crítico literario Hipólito Luna. El protagonista, a quien le queda poco tiempo de vida, teme ser atrapado infraganti durante el acto homicida, no por miedo a ser aprehendido y refundido en una cárcel, sino porque le inquieta no poder terminar con su plan de venganza. Pero más importante aún, teme perder la fama que ha cosechado como escritor gracias 
a la publicación de su bestseller, la trilogía Pene primavera: "cómo matarlo sin que nadie sepa que fui yo quien lo mató y (lo que más me preocupa) sin mancharme en modo alguno" (Bayly, 2010: 43). La ansiedad de que haya habido un testigo o de haber dejado pistas en la escena del crimen que lo conecten con el homicidio de su primera víctima se manifiesta en la manera compulsiva en que Garcés compra y lee todos los periódicos que circulan en Lima y en cómo el asesino ve por horas todos los programas televisivos de noticias a la espera de información que lo implique en el asesinato del crítico.

En la ficción del asesino en serie convencional, tanto el criminal como el representante de la ley participan en el juego del gato y el ratón, en el cual el criminal se vanagloria de no dejarse atrapar y, por ende, de ser más listo que aquel. En contraste, en Morirás mañana, Garcés no es objeto de ningún tipo de investigación ni de búsqueda porque nadie está interesado en descubrir al asesino de los crímenes ocurridos. Las noticias periodísticas revelan que los representantes de la ley están más preocupados e interesados en dar por terminado el asunto criminal sugiriendo, sin investigar, posibles razones del crimen, en su mayoría risibles. Por ejemplo, en el caso del crítico literario, la policía asegura que el asesino fue uno de los esposos de las muchas amantes que tenía el occiso. Con respecto a la muerte de Aristóbulo Pérez, miembro del jurado que votó en contra de Garcés en un premio nacional de novela, los medios declaran que fue un suicidio cuando en realidad se sabe que recibió tres disparos en el corazón. Ante las absurdas especulaciones sobre la muerte de sus víctimas, Garcés es testigo del estado de anomia que impera en el país. Este descubrimiento empodera al inexperto asesino Garcés, quien se jacta de sus crímenes y se alegra por haber nacido en el Perú:

me sentí orgulloso de mis dos crímenes impunes y feliz de vivir en un país donde la policía parecía dirigida por oligofrénicos o por grandes holgazanes que nunca investigaban nada a menos que alguien le pagase por lo bajo para que aclarasen algún entripado. Deduje razonablemente que nadie vincularía el crimen contra Hipólito Luna (bajo sospecha de haber sido cometido por un esposo celoso. [...]) con la muerte de Aristóbulo Pérez (sospechoso de haberse suicidado por depresión severa). (Bayly, 2010: 86)

Se debe observar que, en la construcción del protagonista, Bayly está interesado en resaltar el carácter oportunista de Garcés, quien a pesar de sus temores iniciales puede llevar a cabo exitosamente su plan de venganza sin ningún obstáculo: "Garcés que no tenía planeado convertirse en un asesino en serie, se da cuenta de que vive en el mejor país del mundo para serlo. ¡Acá no te descubren nunca!" (Planas, 2010)

Otro de los rasgos más sobresalientes del subgénero de la ficción de asesinos en serie es que el escritor desarrolla sus obras inspirado en casos criminales de la vida real. Por ejemplo, la novela Zombie (1995) de Joyce Carol Oates se basa en el caso del asesino Jeffrey Dahmer. Por otro lado, muchos escritores cuentan con la colaboración de expertos criminólogos en el tema. Entre ellos, Thomas Harris tuvo como asesor al agente del FBI Robert Ressler, famoso por popularizar la expresión de asesino en serie, para el desarrollo de su popular trilogía (Simpson, 2000: 71). Asimismo, muchos novelistas del subgénero tienen acceso al "research of the FBI's theories and databases regarding serial murder" (Simpson, 2000: 71). Esta cercana cooperación entre los escritores y el FBI ha generado que estas novelas "sanctify, even glorify, the law-enforcement reactive approach to violent crime" (Simpson, 2000: 71). La activa participación de las fuerzas del orden en el proceso creativo literario explica en parte que la representación tanto de la autoridad policial como la de los asesinos en serie en el subgénero siga un esquema clásico literario semejante. 


\section{Representación del asesino en serie en Morirás mañana}

Como se ha ilustrado anteriormente, la trilogía de Morirás mañana claramente subvierte las convenciones del subgénero descritas por Philip Simpson; transgresión literaria que ocurre también con respecto a la representación del asesino en serie. Esta ruptura con el esquema tradicional del subgénero es evidente puesto que, a diferencia de las novelas del país del norte cuyos criminales están inspirados en homicidas de carne y hueso, Bayly no basa la construcción de Javier Garcés en un homicida serial del pasado criminal del Perú o de Latinoamérica. Por el contrario, Bayly, en su afán de provocar a sus lectores y a la crítica, decide modelar el personaje atribuyéndole sus propias cualidades personales, posicionando al asesino como su superego: "Javier, el personaje principal de mis libros, es un disfraz mío en las letras" (RCN Radio, 2012). No es tampoco coincidencia que el autor haya sentido la urgencia de escribir la trilogía en un momento crucial de su vida: cuando, al igual que Garcés, vio su vida en peligro después de que le diagnosticaran una crisis hepática que requería de un trasplante de hígado (Planas, 2010). Por otro lado, la construcción de sus víctimas no es resultado de su creatividad como escritor, sino que se inspira en personas reales del mundo literario. Tras la lectura de la trilogía, el lector puede entrever que uno de los objetivos del autor fue ventilar "la miseria del mundo literario" (Planas, 2010) a través de personajes reales, quienes humillaron en la realidad al escritor Bayly.

Como alter ego del escritor, Javier Garcés comparte muchas de las características de Bayly, pero descritas hiperbólicamente: Garcés es un exitoso escritor que tiene miles de admiradores y fanáticos que desean que escriba otras novelas. El protagonista es extremadamente millonario gracias a la fortuna que le dejaron sus padres al morir, increíblemente engrandecida más tarde por las ingentes ventas de su única obra literaria, la trilogía Pene primavera. Su fama y fortuna le han permitido convertirse en un hombre cosmopolita que no solo viaja alrededor del mundo haciendo entrevistas y conduciendo programas televisivos, sino que también cuenta con varias propiedades fuera del Perú, entre ellas, un apartamento en Buenos Aires. Todos sus éxitos, al igual que sus posesiones materiales, colocan a Garcés en una posición privilegiada dentro de las categorías de la masculinidad, por lo que este se configura como la personificación de la masculinidad hegemónica dentro de la sociedad peruana. No obstante, como el mismo Garcés alega, él no ha ascendido a esta posición gracias a su clase social o su fortuna heredada, sino que ha alcanzado dicha posición dominante en la jerarquía social gracias a su esfuerzo y lucha: "El éxito me lo he forjado fría y calculadamente, se lo he arrebatado a los miserables que pugnaban por negármelo, y lo he conseguido gracias a que soy terco pero, sobre todo, a que soy un gran hijo de puta" (Bayly, 2010: 13).

Debido a su estructura narrativa, Morirás mañana le ofrece al lector la oportunidad de ingresar en la psiquis del protagonista, la cual revela que su asumida masculinidad hegemónica es solamente una apariencia. El lector se entera de que detrás de la imagen de un exitoso ejemplar de la masculinidad dominante se esconde un hombre carcomido por sus miedos, sus angustias y sus malas experiencias con otros. Garcés, quien alardea de ser un talentoso novelista, sufre en realidad de un bloqueo al escribir causado por el temor de revelar con su próxima novela su mediocridad como escritor. El protagonista se considera un hombre de mundo, pero vive en realidad confinado en la antigua mansión de sus padres en el barrio limeño de San Isidro, de la cual solo sale a caminar pocas cuadras a la redonda para realizar sus más inmediatas actividades. A pesar de todos sus logros profesionales, Garcés se siente un perdedor y se deprime con la menor crítica, reflejando con ello la fragilidad de su ego. Asimismo, el personaje no se percibe como un ser con libre albedrío, se cree víctima de las circunstancias causadas por sus enemigos, que, según él, han tratado de hundirlo. En consecuencia, su vida está marcada por el rencor y la inacción. No es 
exagerado señalar que la noticia de su pronta e inesperada muerte representa para él un momento de reevaluación, que le hace reconocer que su vida anterior fue oscura y vacía: "Mi vida nunca tuvo mayor sentido, fue solo una suma de empeños vanidosos" (Bayly, 2010: 16). La noticia de su muerte, consecuentemente, se convierte en un punto de inflexión para Garcés, quien elige la más violenta de todas las expresiones de conducta masculina existentes cuando opta por convertirse en un asesino en serie puesto que anhela vivir: "los mejores meses de mi vida y lo serán porque estarán animados por el afán de venganza y porque ese afán no estará exento de astucia, prudencia y valor" (Bayly, 2010:16).

Uno de los estereotipos más recurrentes en la conducta del asesino en serie dentro de este subgénero es que el homicida se percibe a sí mismo como un: "moral agent and directly voices the many ills he detects, thus revealing a society so ridden with perversity and degeneration that it provides serial killers with a raison dêtre and a moral justification they can adhere to in order to indulge their blood-lust" (Santaulària, 2017: 61). En la trilogía, Garcés también justifica moralmente su nueva conducta asesina al visualizarse a sí mismo como un agente justiciero que con sus múltiples homicidios va a liberar a la sociedad de sus elementos más corrosivos:

No he matado nunca a nadie (quiero decir, no he matado nunca a ninguna criatura humana), pero me ha llegado la hora de educarme en tan noble propósito y de hacer una última e inestimable contribución a la humanidad: limpiarla y purificarla de la presencia hedionda de esos cinco hijos de puta a los que mataré antes de morir. (Bayly, 2010: 15)

Garcés erróneamente se imagina que su aventura criminal es el camino de su redención y trascendencia como persona. Su lógica, sin embargo, es irónica puesto que el protagonista se olvida de que sus propios actos de violencia hunden aún más a la sociedad en la anomia.

En su afán por obtener justicia, Bayly ocupa varias páginas de la trilogía presentando las pruebas, a manera de un juicio, por las cuales los enemigos de Garcés deben morir. El protagonista recrea mentalmente un caso judicial para cada una de sus víctimas, toma la posición de víctima, abogado acusador y juez, y convierte estos pasajes de la novela en un proceso judicial. En estas escenas, Garcés encarna el papel de víctima, primero, enumerando todas las humillaciones que ha sufrido, enfatizando la premeditación, la malicia y el descaro con que sus victimarios cometieron dichas faltas. Después, adopta el rol de un abogado acusador que incrimina a los presuntos culpables, detallando cuidadosamente sus actos delictuosos y el daño emocional y económico que sufrió a manos de cada adversario. Este recurso discursivo contribuye a convencer tanto a los lectores como al mismo Garcés del oprobio al que ha sido sometido (esto contribuye además a que los lectores sientan empatía por el protagonista como víctima). En este proceso judicial, Garcés también se transfigura en juez, quien después de escuchar las evidencias no tiene otra opción, sino la de declarar al acusado culpable e imponerle la sentencia máxima: la muerte.

En las novelas de asesinos en serie convencionales, el detective o la autoridad policial crea un relato de ficción para establecer cómo ocurrió el acto homicida a partir de las pistas que encuentra en la escena del crimen y, principalmente, a través de las evidencias halladas en el cuerpo de la víctima. En contraste, el homicida Garcés es quien elabora una narrativa prediciendo lo que va a ocurrir en la escena del crimen. Para crear dicha narración, el protagonista se comporta como un asesino metódico que rastrea a sus enemigos sigilosamente para investigar sus comportamientos y sus rutinas, no solamente para determinar el lugar donde será más fácil aniquilarlos, sino para anticipar cómo van a reaccionar ante la situación de peligro. Además de 
recrear esta narrativa, Garcés visualiza cómo debe actuar para dominar la situación y someter a sus adversarios. Este personaje muestra que no es el tipo de asesino que se conforma solamente con eliminar a sus enemigos y dejarlos muertos en la escena del crimen, sino que exige ser redimido al obligarles a sus víctimas a que confiesen su delito y que se arrepientan. Tal es el caso del crítico literario que confiesa antes de morir: "De todos modos, te pido mil disculpas, Javier, si fui demasiado duro en mis críticas. Creo que se me pasó un poco la mano, pero, tú sabes, a la gente del periódico le gusta que mis críticas sean [.. .] un poquito cáusticas" (Bayly: 2010, 48).

Dado el grado de premeditación y metodología con que desarrolla sus primeros cuatro asesinatos en el Perú, Garcés se caracteriza por ser un asesino organizado. Según el reporte del FBI escrito por Robert Ressler, "Violent Crimes", los asesinos seriales se clasifican en homicidas organizados y desorganizados (1985: 18-19). El primer tipo de asesino se caracteriza por planificar con anticipación el crimen, escoger a la víctima cuidadosamente y tenerla bajo control durante el acto homicida (Ressler: 1985, 20). En cambio, el asesino desorganizado no realiza un plan de antemano y asesina de manera espontánea e impulsiva sin tener una víctima en particular en mente (Ressler: 1985: 22-23). El reporte de Reesler establece un perfil psicológico y las maneras en que el homicida actúa antes y durante el crimen. El perfil que desarrolla el FBI sobre el asesino organizado acierta en varios rasgos que presenta Garcés: inteligencia promedio a superior, competencia social y estado de ánimo controlado durante el crimen (Ressler, 1985: 19). La conducta que exhibe el protagonista durante el acto criminal corresponde también a esta categoría: ofensa planificada, personalización de la víctima, conversación controlada, sumisión completa de la víctima en la escena del crimen (Ressler, 1985: 19).

En la literatura de asesinos en serie convencional, las víctimas son principalmente personajes anónimos y pasivos a las cuales el victimario inflige daño; sus cuerpos inertes funcionan como evidencia de la agresividad, violencia y sadismo del criminal. Sobre la función de las víctimas en esta narrativa, Emily O'Grady y Sarah Holland señalan que el escritor está tan interesado por elevar al asesino en serie a la estatura de un mito que "renders the victims of murders invisible" (2019:36). Morirás mañana se aparta de esta representación de la víctima porque el protagonista no solamente incluye a la futura víctima/enemigo en un proceso judicial que ocurre en la mente de aquel para declararlo culpable, sino que lo personaliza y le provee una voz, especialmente cuando Garcés le sigue el rastro para aprender sobre sus manías, debilidades y vicios. En el decurso de la trilogía, el personaje de Alma Rossi, la víctima número cinco en la lista de personas que Garcés decide asesinar en Lima, se convierte en un personaje tan importante en el devenir de las tres entregas de la trilogía que llega muchas veces a eclipsar al protagonista. Según este último, Alma Rossi merece morir porque lo traicionó con el editor Jorge Echeverría, víctima número cuatro, al transferirle a este la editorial que fundaron juntos Rossi y Garcés. No solo Rossi engañó económicamente a Garcés, sino que el editor y Rossi se volvieron amantes, y dejaron al protagonista maltrecho por la traición amorosa. En su complejo plan criminal para acabar con Echeverría y Rossi, Garcés utiliza a Rossi como carnada para asesinar a Echeverría obligándola a alquilar un cuarto de hotel para que su amante se reúna con ella y matarlos a ambos. Garcés, a pesar de ser un asesino organizado que sigue metódicamente su plan, solamente asesina a Echeverría pues en el último momento se arrepiente de asesinar a la mujer: "Quiero odiarla, necesito odiarla para matarla, pero veo sus labios temblando de miedo y no puedo, esos labios me han dado momentos de felicidad que sobrepasaban largamente a los de rabia, despecho y odio" (Bayly, 2010: 134).

En el decurso de Morirás mañana, Alma Rossi se convierte en el hilo conductor de la trama en la medida en que este personaje y Garcés participan en un juego de gato y 
ratón en el que ambos viajan a Chile y posteriormente a Argentina persiguiéndose con la finalidad de matarse. El inicio de esta persecución se desarrolla a la manera de un cliffhanger al final del primer libro cuando Rossi se escapa a Chile llevándose dos millones de dólares y el auto deportivo de Garcés. Rossi deja Lima sin enterarse de que él no va a morir ya que la noticia de su enfermedad ha sido un error que comete el doctor al leer las radiografías de un tal Javier García. No es exagerado señalar que Rossi, debido a su oscuro pasado y a sus acciones en contra de Garcés, encarna a la femme fatale. En su estudio sobre este tipo de personaje femenino, Annette Kuhn señala que este arquetipo es: "primarily defined by her desirable, but dangerous, sexuality which brings about the downfall of the male protagonist" (1990: 154). En el devenir de la novela, Rossi convence a uno de sus amigos de asesinar a Garcés en Chile; y en Argentina, es ella misma quien elimina a Garcés al final de la trilogía.

En Morirás mañana, el lector es testigo de la metamorfosis que ocurre en la conducta asesina de Garcés. Si en la primera entrega el protagonista cree que su rol es clamar justicia y eliminar a los malos elementos de la sociedad, después de sus asesinatos en Chile, que ocurren en el segundo libro, el comportamiento criminal del protagonista da un giro radical. Su actividad criminal se transforma en un acto placentero, en una adicción: "Antes era adicto a escribir novelas. Ahora soy adicto a matar personas a las que odio o desprecio, o a las que simplemente me divierte matar" (Bayly, 2012: 9). En cambio, en Argentina, después de haber seleccionado a sus próximas cinco víctimas, Garcés imagina que como asesino está realizando una labor redentora por la cual va a recibir el perdón de Dios porque ha cometido "unos crímenes que, no lo dudo, si hay Dios, me serán agradecidos por su divina providencia (pues he hecho el trabajo de baja policía o recogedor de basura para que el Altísimo no ensucie sus manos)" (Bayly, 2012: 106).

Con respecto a sus asesinatos múltiples, Garcés compara el goce que experimenta cuando asesina con la experiencia estética de crear un objeto de arte. La conexión entre la creación artística y el homicidio es una temática muy común en la narrativa del asesino en serie convencional, inspirada en la tradición romántica (Simpson, 2000: 22). La experiencia estética y la homicida confluyen en el pasaje donde Garcés apuñala mortalmente a Pedro Vidal, gerente de una estación de televisión chilena:

Qué rico fue hundir ese cuchillo en la panza de esa araña. Fue mucho mejor que matar a balazos. Pude sentir la punta de mi arma revolviendo sus tripas y distinguir en su aliento entrecortado los estertores de la muerte. [... .] Ser escritor era un aburrimiento del carajo; matar a Pedro Vidal a cuchilladas y luego quemarlo ha sido el momento más perfecto (moral y estéticamente perfecto) de mi vida. (Bayly, 2011: 56-57)

En Morirás mañana, la conexión entre el arte y el acto homicida se trastoca en una relación simbiótica en la medida en que su adicción por asesinar despierta su deseo por escribir de nuevo. No es casualidad que la necesidad de asesinar a su enemiga, Alma Rossi, lo impulse a escribir un libro que revele los más recónditos secretos de ella y su familia: que Rossi asesinó a su madre y mantuvo una relación incestuosa con la persona que creía ser su padre, entre otros. Garcés, por lo tanto, se encuentra en una misión homicida que no solamente incluye asesinar físicamente a Rossi, sino también destruirla simbólicamente mediante el acto de escritura de un libro controversial.

Tanto en los casos reales como en la ficción tradicional, a los asesinos en serie se los asocia con crímenes sexuales dirigidos principalmente a mujeres con las cuales tratan de recrear sus violentas y sádicas fantasías sexuales. En la trilogía Morirás mañana, Bayly no recurre a este Leitmotiv ya que sus crímenes están exentos de cualquier connotación sexual. De hecho, el número de víctimas féminas es increíblemente 
reducido en comparación al de los hombres. Garcés asesina solamente a la dueña de una librería, la argentina Lola Repetto, y casi mata a Alma Rossi, quien se despierta de un largo coma después de que Garcés le dispara en el pecho al final de la segunda entrega. Estos dos crímenes no tienen motivos sexuales, ni su ejecución está marcada por una práctica sexual aberrante. Sin embargo, es importante recalcar el impacto que tiene la presunta muerte de Rossi en el comportamiento de Garcés, ya que su muerte trastoca su conducta homicida. Su deseo de matar se desborda al punto de asesinar por capricho y por razones mezquinas, tales como al vecino por su flatulencia o a un prestigioso chef por cobrarle la cena. El asesino organizado que seguía metódicamente el plan homicida se transforma ahora en un asesino desordenado e improvisado, al que no le interesa ser atrapado por las fuerzas policiales en Argentina con tal de asesinar a las personas de su lista. No obstante, Garcés no muere de manera gloriosa como los grandes asesinos en serie a manos de las fuerzas del orden, tal como se narra en la literatura de crímenes seriales, sino que, deseoso de acabar con su adicción de matar, es Rossi quien misericordiosamente lo ejecuta con un certero disparo en el pecho.

A lo largo de los tres libros de la trilogía, Javier Garcés llega a eliminar a catorce de sus enemigos y a otras dos personas que forman parte del daño colateral como resultado de la adopción de una conducta masculina extrema: la de asesino en serie. En Morirás mañana, el lector ingresa en una realidad esperpéntica, grotesca y deforme, en la cual la muerte adquiere un carácter banal debido a su representación horrenda, ridícula y cómica, que, si bien cumple las expectativas de entretenimiento de los lectores, no significa que siga las convenciones literarias del subgénero de asesinos en serie. En su lugar, la obra de Bayly se distingue por romper muchas de las características del subgénero y logra con ello que el lector se coloque al otro lado de la ley, en un mundo donde la línea que separa lo justo de lo injusto ya no existe. En ausencia de representantes de la ley y de castigo, Garcés le ruega al amor de su vida que lo mate: el asesino en serie no se glorifica con una muerte climática, sino que termina donde comenzó, como un hombre lleno de rencores y remordimientos que son finalmente aplacados con su insignificante y poco espectacular muerte. Estas singulares características permiten afirmar que la trilogía Morirás mañana es una importante contribución literaria al subgénero en la medida en que propone nuevos rumbos a la novela de asesinos en serie en Latinoamérica. 


\section{Q Bibliografía}

"Baelo, S. (2002). "The Aesthetics of Serial Killing: Working Against Ethics in 'The Silence of the Lambs' (1988) and 'American Psycho' (1991)”. Atlantis, 24.2, 7-24.

» Bayly, J. (2010). Morirás mañana: El escritor sale a matar. Doral: Santillana.

»Bayly, J. (2011). Morirás mañana: El secreto de Alma Rossi. Doral: Santillana.

» Bayly, J. (2012). Morirás mañana: Escupirán sobre mi tumba. Doral: Santillana.

»Cabrera, E. (2016). “'La parte de los crímenes’ en 2666: la visibilización del concepto ‘feminicidio' como política de la literatura”. Letral, 16, 26-37.

»Isuani, E. (1995). “Anomia social y anemia estatal: Sobre la integración social en Argentina”. En: Filmus, D. (ed). Los Noventa. Política, sociedad y cultura en América Latina. Buenos Aires: Flacso Eudeba, 25-51.

» Jenkins, P. (1994). Using Murder: The Social Construction of Serial Homicide. New Brunswick: Aldine Transaction.

» Kuhn, A. (1990). Women's Companion to International Film. London: Virago Press.

»Oates, J. C. (1999). “Three American Gothics”. En: Oates, J. C. (ed.). Where l've Been, and Where l'm Going: Essays, Reviews, and Prose. New York: Plume, 232-243.

» O’Grady, E. y Holland, S. (2019). "Complicating the Serial Killer Novel: The Bystander Narrator as Genre Disrupter". New Writing 16.3, 363-373.

" Orué, R. (2012). “Morirás mañana - Jaime Bayly". En: https://roxanaorue. com/2014/o4/20/critica-moriras-manana-jaime-bayly/; obtenido el 26/05/2020.

»Planas, E. (2010). "Jaime Bayly aseguró que los enemigos que mata en su libro están inspirados en personas reales". En: https://archivo.elcomercio.pe/luces/ arte/jaime-bayly-confeso-enemigos-que-mata-su-nuevo-libro-estan-inspirados-personas-reales-noticia-613129; obtenido el 26/05/2020.

»Perú 21. (2005). “Jaime Bayly reaviva la polémica del premio Planeta al responder a Marsé". En: http://archivo.peru21.pe/noticia/64405/jaimebayly-reaviva-polemica-premio-planeta-al-responder-marse; obtenido el 05/07/2020.

» RCN Radio. (2012). "Morirás mañana, la respuesta de Jaime Bayly a sus enemigos imaginarios". En:https://www.rcnradio.com/entretenimiento/moriras-manana-la-respuesta-de-jaime-bayly-sus-enemigos-imaginarios-16092; obtenido el 25/05/2020.

» Ressler, R. y Burgess, A. (1985). “Violent Crimes”. FBI Law Enforcement Bulletin, 54.8, 2-31.

»Reyes, M. (2008). “Anomia y criminalidad: Un recorrido a través del desarrollo conceptual del término anomia”. Criminalidad, 50, 319-332.

»Santaulària, I. (2007). “'The Great Good Place’ No More? Integrating and Dismantling Oppositional Discourse in Some Recent Examples of Serial Killer Fiction". Atlantis, 29, 55-67.

"Seltzer, M. (1998). Serial Killers: Death and Life in America's Wound Culture. New York: Routledge. 
"Simpson, P. (2000). Psycho Paths: Tracking the Serial Killer Through Contemporary American Film and Fiction. Carbondale: Southern Illinois UP.

"Vásquez, A. (2016). “Un hijo sano del patriarcado. Feminicidio en la novela No me ignores de Nicolás Poblete”. Estudios filológicos, 57, 149-165. 
